tain a uniform succession of carriages each way, by means of ropes, alternately winding and unwinding upon drum wheels, eight feet in diameter.

On one of the inclined planes, the ropes are upwards of two miles in length, being supported by light cast iron concave rollers, fixed at a distance of forty or fifty feet apart, in the centre of the way, between the rails; and as the ropes are wound on and off the Urum, the small rollers revolve, and keep them from coming in contact with the soil of the road.

Where the road-way deviates from a straight line, in plan, or where the plane winds to the right or left, the axes of the rollers are placed in nearly a vertical direction; in order to keep the line of draught midway between the rails.

It will be perceived by the engraved view, that this road is formed over an undulating, or hilly country; and that the transportation of all the articles from the collieries and its neighbourhood, is malle to surmount a series of very considerable ascents, by means of fixed engines, placed on their summits; and the motion given by these machines to the wagons reciprocally, is equal to nine miles an hour.

The rails are made of cast iron, four feet in length; and are known generally, by the denomination of the edge, or round top rail, of Losti \& Stephenson.

The loco-motive engines are made of thick sheet iron, and aro obviously of the high-pressure kind; they are only made to ply upon level lines of road; for the engine itgelf, in any material ascent, consumes a great portion of its power in the movement of its own weight, and that of its fuel; and any sudden rise would annihilate its object and use.

\title{
NATURAL HISTORY.*
}

Few departments of knowledge, have been more injured by incorrect or prejudiced views of their real character, than Natural History; which some regard as a mere collection of tales for the amusement of children, or idlers; and others, as an aggregation of learned lumber, too heavy for use, and too harsh to be interesting. 'That such notions are not altogether unwarranted by those who have been called Naturalists, is too true; many of their books being filled with the most incredible nonsense, while a very large number of those claiming to rank as purely scientific, are little better than Dictionaries, in which the authors have tasked their ingenuity, to accunulate all the harsh and barbarous terms they could compound from various living and dead languages. Yet granting thus much, by no means renders it fair to argue against the usefulness of Natural History, from the abuses which have been cloaked under

* Dr. Codman, professor of Natural History in the Institute, has engaged to become a contributor to, and to aid the Editor in conducting this department
of the Journal. 
its name, a similar mode of reasoning, might 1 tad to the regection of the most admirable and valuable institutions, since we cantot find one, however excellent, which has not in some degree been abused.

Another prejudice which has tended to retard the diffuston of 4 proper knowledge of Natural History, is the idea that a great deal of learning is necessary to beginners of this study. Hence, many excellent opportunities have been entirely lost of observing and establishing facts, concerning which the world may long remain in doubt; those who have enjoyed such opportunities, have supposed it necessary that they should be very learned, befure they would have a right to announce what they had seen. It is most true that preliminary education is of great advantage in all Sciences and Arts; but in Natural History, which is almost exclusively a science of observation, a close attention to facts seen, and an accurate re: lation of them as they occur, are of more value than the most learned discussion, and would be certainly far more acceptable, than the highest refinements of speculation. All the learning that is necessary for any one to become practically (which is, usefully) acquainted with Natural History, is a sufficient degree of intellectual cultivation, to save him from seeing incorrectly, or mistaking secondary, for the primary, and really important circumstances. For instance, it was long supposed by observers, that the Skunk (or Pole-cat, as it is popularly called,) diffused its powerfully offensive odour by sprinkling a fluid on its disturbers with its bushy tail; and this silly notion has been repeated until very recently, even by grave authors. More accurate observation has shown that the animal raises the tail suddenly, previous to the dif:fusion of the offensive liquor; and in order to prevent this substance from touching it, being peculiarly clean and neat in its own person. Various analogous cases may occur, in which incorrect conclusions might be drawn, without some preparatory knowledge; but with the proper care in making observations, or stating the actual condition of facts, even incorrect conclusions, will be comparatively harmless.

Every man of ordinary capacity, may stady Natural History tor himself, and advantageously too, if he be really desirous to form an acquaintance with Nature through her works, rather than to shine as a framer of systems, or a composer of theories. To study $\mathrm{Na}$ tural History, it is only necessary for us to use our eyesight-to look upon the multitudes of living beings by which we are surrounded, observe their peculiar construction and adaptation to the places they occupy, their modes of living, and the relations they bear to other animals, and to man himself: this is the study of Natural History. The fruitless and wearying discussion of technical phrases, or the propriety of various classico-barbarous appellations, with hair splitting distinctions of genera, sub-genera, species and varieties, is nor Natural History, but the stuly of Nomenclature; a dry and barren waste! tenanted only by fierce and fruitless iealousies, recriminations and disquiets of every degree!

Vox. I,-No. 1,-. TANVARX, 182h, 
The study of Natural History is too beneficial in its influence, to allow of its being restricted to the few who are able to approach it through the severe and uninviting method of arbitrary and artificial classification. As its immediate tendency is to enlighten the mind, and warm the heart; to enlarge our feelings of respect for our own race, and enable us more correctly to appreciate the beneficent wislom of the Creator, we believe that those writers who endeavour to render Natural History generally accessible, confer more benefit on mankind, than if they filled whole libraries with books of the deepest learning, too abstruse to be generally read; therefore but seldom approached, and still more seldom understood.

The difference between learning, and wisdom, is never more clearly perceived, than when we observe the conduct of those who mistake Classificalion and Nomenclature, for Natural History; and violently object to every effort made to diffuse knowledge, without the shackles they have imposed on themselves. Many such men are truly and deeply learned, but they certainly are not wise, when they forget that classifying, and naming, are only among the means of acquiring knowledge, and are not the end we have in view; that scientilic arrangements are mere instments to work withal; that systems at best serve the purpose of an index; that they are arbitrary and mutable; always the productions of Art, and seldom having much affinity with Nature.

Nevertheless, a good machine to work with, is extremely desirable; and the best system we can find, is an excellent aid in the study of Natural Objects, provided we never once forget, that the system at best is but a tool with which we are to accomplish a very important work, the collection and arrangement of useful knowledge. Such a system, as far as utility is concerned, has been formed by Gonge Cuvren, (better, and more emphatically known as Cuvien.) founded on characters furnished by the Anatomy of Animals. Their rank in the scale, is determined by their degree of approach to the construction of the human body; and their relations to each other, determined by their peculiar regimen or modes of life, and organs of digestion-as indicated by the subsidiary apparatus for the seizure, and mastication of their food.

Our object in thus endeavouring to invite more general attention to this delightful study, is to open a new and most ample source of gratification to many, who have both leisure and opportunities for observation, but are withheld by mistaken notions. There is in fact, a vast deal yet to be observed, before the Natural History, of even our most common animals, can be completed; and cvery actual observation, will be of the highest value. Independent of this, as a source of individual gratification, it is not to be excelled; seeing that the objects of nature are boundless, and the field is open to all. It is not in books that we are to find nature; though they may aid us in planning our walks, or in guiding our observations; but it is in the fields and wools, in the plain, and on the mountain, by the side of the rippling brook, or on the sandy beach lashed by ocean's foaming water's, that the student must look, with 
the fullest certainty, of finding objects capable of rewarding his search; and opening his eyes to perceive, that the works of the Creator, are best to be understood when read from that great book which is accessible to all, and is unobscured by gloss or commentary.

\section{Remarks on an Article in the North American Review.}

The last number of the North American Review, (50th) contains a criticism on a work published sometime since in this city, entitled "Fauna Americana." This article contains many judicious and useful remarks, written in a candid and manly style; yot to judge merely from the review itself, one might infer that the writer was not technically familiar with the subject before him; and al though he has given numerous proofs of discrimination and judgment, does not appear fully to understand the actual condition, "the form and pressure" of scientific Natural History, as it now exists. We say he appears to be in this condition, for we have no mode of judging of his standing, except through the review before us. The impression we have received from reading this criticism is, that it is written by one accustomed to close thinking and sound logic; but not practically and technically, a Naturalist; to whom the glaring faults of the book have been pointed out by one familiar with the subject, but in a desultory manner; in short, by a person who is an admirer of Natural History, but not a closely applied, or profound student of the science. Such is our impression; though we well know how easy it is to be mistaken.

The writer of the review, has truly found a very sufficient number of faults in the "Fauna," but a technical critic would have attributed these faults to $M$. Desmanest in very great part, and not to the American "Author ;" since, out of three hundred and fourteen pages, very nearly, if not quite, two hundred and fifty. are verbally and literally translated from the "Mammalogie" of the French Nataralist. This a tecknical critic ought to have knowh. The faults for which the American Author is really responsible, (although he did actually assume the others,) are those parts which are considered as peculiarly original, in the "Fauna," and these are certainly not few. Except these original errors, the whole of the rest should be charged to Desmarest; he it is, who should be scolded for not introducing the extracts from Bonnaterre's "Cetologie," as it is he, who quoted this writer. We believe that the author of the "Fauna" never saw that work; nay, we are almost sure it has not yet reached America.

A technical critic would have known better than to elevate to the rank of an original work, such a one as the "Fauna," under whatever guise it might be presented to the world. A reviewer is, with no great impropriety, supposed to know all things relative to the subject on which he writes; or, in other words, the publication of a review, presupposes that the writer has taken pains to acquire 